\title{
EL PROYECTO DEL CANAL DEL ALGAR DE FRANCISCO MORELL: UNA INICIATIVA TEMPRANA DEL REGENERACIONISMO HIDRÁULICO EN ALICANTE ${ }^{1}$
}

\author{
Antonio José Romero Pastor \\ Colegio Padre Dehon. Novelda (Alicante) \\ aromerop@doc.colegiopadredehon.com
}

La huerta de Callosa pasa de 500 jornales, y la porción principal de ella se halla entre los ríos Algár y Guadalést. Mayor sería si los vecinos pudieran aprovechar como ántes las aguas de Algár, cuyo nacimiento está 20 varas mas alto que los campos, y los industriosos labradores las dirigian por canales para fertilizar tierras que hoy carecen de riego (...).

Cavanilles, A. J. Observaciones sobre la historia natural, geografía, agricultura, población y frutos del Reyno de Valencia, 1795-1797

\section{RESUMEN}

Por sus características climáticas, en la región mediterránea del sureste han tenido históricamente destacado protagonismo las obras y proyectos hidráulicos. La hegemonía que mantiene la actividad agrícola en España, aún en la segunda mitad del siglo XIX, por el retraso en la adopción de los modelos industriales, favoreció, al amparo de un incipiente liberalismo, modelos de crecimiento económico de corte agrarista en los que el regadío y las obras hidráulicas fueron elementos destacados. En la provincia de Alicante, el proyecto del Canal del Algar del arquitecto valenciano Francisco Morell es un ejemplo. El presente artículo trata de justificar cómo, en Alicante, y favorecido por este contexto, aparece en 1866 el Proyecto de un canal de riego que anticipa, en muchos de sus planteamientos y propuestas, la ideología del movimiento regeneracionista.

Palabras clave: Regadío, canal de riego, Regeneracionismo, agrarismo.

\section{ABSTRACT}

\section{The Algar Canal Project by Francisco Morell: an early initiative of hydraulic regenerationism in Alicante}

Because of its climatic characteristics, in the South Eastern region of the Mediterranean, hydraulic projects and works have been historically popular. The hegemony that maintained agricultural activity in Spain, although in the second half of the $19^{\text {th }}$ century due to the delay in adopting industrial models, favoured, under incipient liberalism, models of economic growth of the agrarian sector in which irrigation and hydraulic works were prominent. In the province of Alicante, the Algar Canal project, by the Valencian architect Francisco Morell is an example. This paper attempts to justify how, in Alicante, and chosen because of that, in 1866 the project of canal irrigation arose that anticipated, in many of its approaches and proposals, the ideology of a regenerationist movement.

Keywords: Irrigation, irrigation canal, Regenerationism, agrarian.

\footnotetext{
1 El presente artículo es una ampliación del trabajo fin de Máster en Planificación y Gestión de Riesgos Naturales de la Universidad de Alicante que, presentado con el título La consideración del riesgo de sequía en la Política hidráulica española, fue defendido en septiembre de 2011. El trabajo fue dirigido por el profesor D. Pablo Giménez Font.
} 


\section{INTRODUCCIÓN}

Los viajes del agua han sido siempre una constante en las tierras del sureste peninsular. Desde el Reformismo Ilustrado hasta la actualidad, los trasvases han estado presentes con mayor o menor protagonismo en cualquier planteamiento de planificación hidrológica. Los contrastes físicos, climáticos e hídricos que encontramos en la provincia de Alicante dotan a esta de una singularidad en el conjunto de las tierras del sureste peninsular: a las comarcas más septentrionales, la Marina Alta, montañosas y con una pluviosidad relativamente abundante, se le oponen los sectores del Bajo Segura y Bajo Vinalopó, a las puertas de la España semiárida.

El agrarismo y, por extensión, la política hidráulica fueron, bajo los soportes ideológicos del regeneracionismo, dos de los pilares fundamentales sobre los que se tenía que sustentar la ansiada regeneración de la patria.

En el último tercio del siglo XIX, cuando aún en Alicante la agricultura es la base económica de una incipiente burguesía agraria, ve la luz el Proyecto de Canal de riego del arquitecto valenciano Francisco Morell y Gómez. El magno proyecto tratará de derivar las aguas del río Algar hacia las comarcas del campo de Alicante en un intento de combatir uno de los males seculares de estas tierras: las sequías.

Cuando ni tan siquiera las bases de la política hidráulica regeneracionista están, si acaso, aún, planteadas, Morell, en muchas de las justificaciones al Proyecto, apunta algunos principios de lo que posteriormente será lo más genuino del movimiento regeneracionista: el agrarismo y la política hidráulica.

\section{LOS CONDICIONANTES FÍSICO-CLIMÁTICOS DE LA PROVINCIA DE ALICANTE FAVORABLES AL PROYECTO}

La provincia de Alicante se localiza en la región climática del sureste. De su pertenencia al dominio climático mediterráneo se derivan, entre otras consecuencias, una pluviometría escasa e irregular, hándicap histórico para el desarrollo de la práctica agrícola.

Figura 1. Localización de la provincia de Alicante

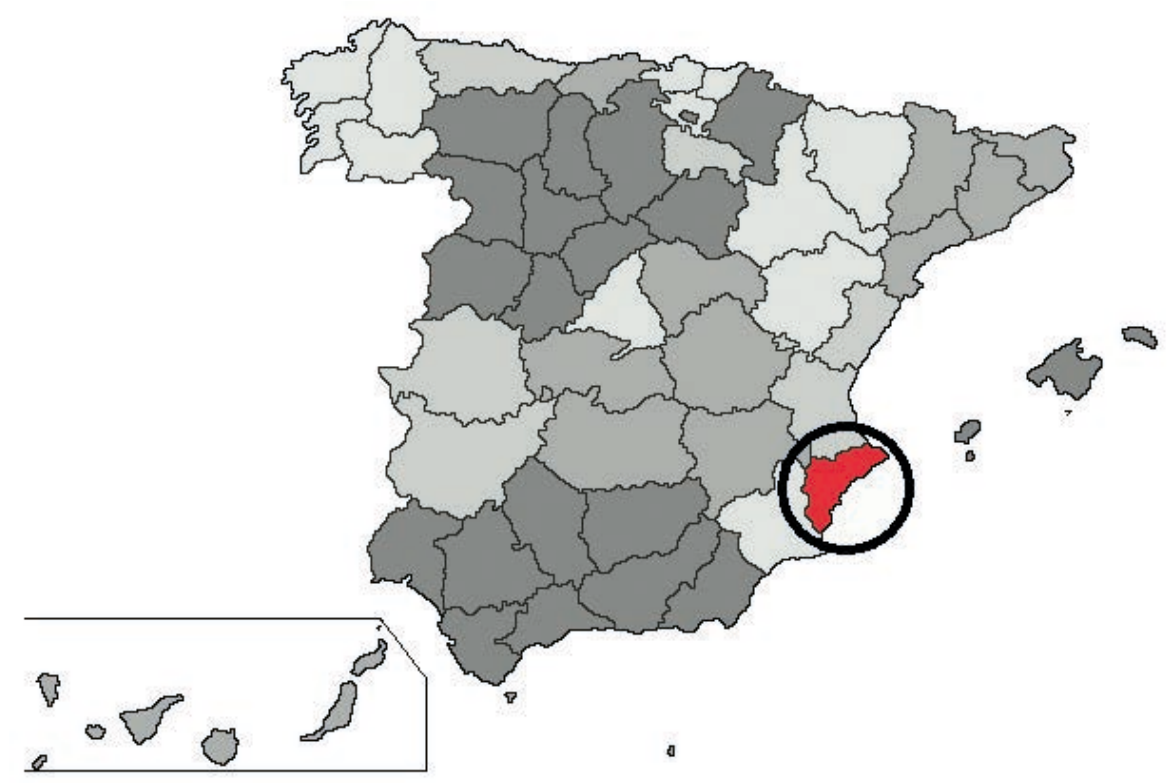

Con carácter general, la escasez pluviométrica, máxima en la estación estival, se produce por la confluencia de una serie de factores físicos y atmosféricos, entre los que destacan, entre otros, la proximidad al máximo de Azores o la posición a sotavento de los flujos atlánticos. Junto con la escasez, la irregularidad sería la otra componente que destaca de las precipitaciones en estas tierras: en la mayor parte de la provincia la precipitación se concentra entre $15-20 \%$ de días al año. Precipitación que, en no pocas ocasiones, se presenta con acusada torrencialidad y concentración horaria, de tal manera que, en unas horas o en pocos días, se superan los valores medios anuales. La elevada temperatura del Mediterráneo, 
responsable de la formación de una masa de aire cálida y húmeda, el desarrollo sobre el mar Mediterráneo de una depresión fría y la estructura orográfica litoral son algunos de los factores que justificarían estos diluvios que, por lo general, y en época tardoestival, azotan las tierras alicantinas.

Si de la posición de la provincia se deriva esta dualidad, no menos importante es el protagonismo que adquiere la orografía. Adscrita la mayor parte de la provincia al dominio Bético (Prebético de Alicante), la orografía, accidentada y compleja, así como la orientación de las vertientes, establece contrastes climáticos significativos especialmente entre la costa y el interior, pero, igualmente, entre los sectores septentrionales y los meridionales. Son acusadas las diferencias térmicas y pluviométricas, incluso, entre comarcas próximas, siendo frecuentes los islotes y las sombras pluviométricas.

Vinculadas las tierras provinciales al dominio climático mediterráneo, sin embargo, los factores físicos y atmosféricos dificultan la homogeneización del territorio bajo tales premisas. Consecuencia de ello es la división climática de la provincia de Alicante en dos áreas o subregiones: una septentrional sub-húmeda, húmeda incluso, y otra centromeridional, semiárida.

En general, la precipitación disminuye de norte a sur. Los valores máximos de precipitación se registran en la región septentrional, donde se superan los $1000 \mathrm{~mm}$. y, aun, en años húmedos, los $1200 \mathrm{~mm}$., mientras que enclaves del sur provincial, Bajo Segura y Medio y Bajo Vinalopó, no superan los 300 mm., ni aun los $250 \mathrm{~mm}$. Esta variabilidad espacial no pasa inadvertida para Francisco Morell, que, en su justificación al Proyecto del Canal del Algar y en la descripción de la comarca de la cual ha de partir el mismo, la describe como una "región hidrográfica que está fuera de las condiciones climatológicas y topográficas de esta comarca, condiciones que determinan la escasez de lluvias" (Morell, 1866: 9).

Se suma a la variabilidad espacial una destacada irregularidad interanual y aun estacional: a los años secos les suceden años extremadamente húmedos que ponen en entredicho los valores medios de las diferentes regiones pluviométricas: las sequías son, en consecuencia, el problema secular al que se ha enfrentado el agro alicantino: "hubiera sido un verdadero paraiso [Alicante], si las proverbiales sequías de su territorio que los romanos llamaron espartario, no hubieran opuesto constantemente un obstáculo insuperable al completo desarrollo de su agricultura" (Morell, 1866: 5), de tal manera que las alusiones y referencias a las mismas, así como a sus catastróficas consecuencias, son constantes en todo el Proyecto.

La disimetría pluviométrica entre el norte y el sur de la provincia de Alicante pone de manifiesto el protagonismo que adquiere el relieve y la orientación de las vertientes en la distribución de las precipitaciones. En "las vertientes del lado N. dentro de los límites de nuestra provincia, que dan origen a los ríos Serpis, Gallinera, Girona, Alberca y Gorgos, que desembocan todos ellos en el golfo de Valencia" (Morell, 1866: 11), la precipitación media supera los $700 \mathrm{~mm}$., esto es, en las vertientes orientadas a los flujos húmedos de levante de las sierras alicantinas de Bernia, Carrascal de Parcent, Serrella o Benicadell. Este conjunto de sierras ejercería de divisoria de aguas respecto a las cuencas centrales de la provincia, en cuyas "vertientes del S. nacen o se deslizan los ríos Binalopó, Castalla, Villajoyosa, Torres, Chirles, de Guadalest o Callosa, el Bolulla y el Algar" (Morell, 1866: 11), cuencas que tienen una atención preferente en el Proyecto de Morell -Algar, Amadorio o Seco- y que, a sotavento de los flujos húmedos de levante, darían paso a la mitad sur de la provincia, donde las características semiáridas adquieren protagonismo; tal es el caso de las comarcas de Bajo Segura/Vinalopó.

Por lo que respecta a las temperaturas, la mayor parte de las tierras alicantinas son partícipes de los valores que caracterizan al clima mediterráneo. Madoz lo describe como un "clima templado, si bien algo caluroso hacia la costa, y demasiado frío en los puntos elevados" (Madoz, 1865: 608). Los contrastes, al igual que con la distribución de las precipitaciones, se justifican por los rasgos físicos. La altitud de las comarcas interiores y la continentalidad del Alto Vinalopó determinarían los valores mínimos inferiores a $13^{\circ} \mathrm{C}$, mientras que los valores máximos los encontramos en las proximidades de la costa y en los sectores más meridionales, con valores que oscilan entre los $17-19^{\circ} \mathrm{C}$, comarcas del Bajo Segura, Vinalopó Medio y Bajo, Marina Baja y en el Campo de Alicante. Los inviernos, benignos en la costa, con valores medios en torno a los $11^{\circ} \mathrm{C}$, contrastan con los registros del interior, con valores relativamente bajos, entre $4-6^{\circ} \mathrm{C}$, y donde no son infrecuentes las heladas y, en ocasiones, copiosas nevadas, tal como refiere Morell al describir la cabecera del río Guadalest, "que se alimenta de las lluvias caídas en su región y de las grandes cantidades de nieve que cubren sus extensas montañas" (Morell, 1866: 17).

Los recursos hídricos subterráneos tienen destacado protagonismo en la Demarcación Hidrográfica del Júcar y, en especial, en la provincia de Alicante. Según afirma Torregrosa (2009: 54), los recursos 
medios disponibles en régimen natural en dicha Demarcación son del orden de unos $3.250 \mathrm{Hm}^{3} / a n ̃ o$ : de

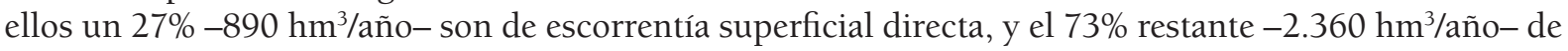
escorrentía subterránea. Esta realidad no pasa inadvertida para el autor del proyecto, que, en la Descripción Geográfica del terreno y de las Cuencas comprendidas en él, destaca las características hidrogeológicas provinciales al afirmar que "conviene tener presente que desde la provincia de Cuenca viene la cordillera en continuo descenso, y no sería imposible que las capas impermeables, hicieran llegar por filtración los productos de lluvia en toda su extensión, hasta aumentar el agua de los ríos que describiremos más adelante" (Morell, 1866: 11). Efectivamente, son numerosas las referencias a manantiales y fuentes que alimentan los caudales de los ríos descritos -Algar, Bolulla, Guadalest, Chirles o Villajoyosa-, en especial en el sistema Algar-Bolulla-Guadalest. Así, el Mapa del Agua de la Provincia de Alicante (2007: 22) recoge que "la superficie de materiales permeables en la provincia ocupa un total de $3.600 \mathrm{Km}^{2}$, de los que $1.228 \mathrm{Km}^{2}$ presentan permeabilidad alta o muy alta; $652 \mathrm{Km}^{2}$ permeabilidad media y $1.720 \mathrm{Km}^{2}$, baja. La superficie restante, $2.263 \mathrm{Km}^{2}$, está ocupada por materiales prácticamente impermeables".

La pertenencia de Alicante a los dominios Béticos, junto con la complejidad geológica y tectónica de la misma, justifica la diferencia de los materiales entre los sectores centro-norte y sur. La preeminencia de materiales secundarios y aun terciarios en el centro y norte de la provincia otorgaría mayor presencia a los materiales carbonatados, bien alternando con materiales impermeables, margas, bien de alta permeabilidad, calizas y dolomías; por el contrario, en los terrenos del Campo de Alicante y Bajo Segura son hegemónicos los terrenos cuaternarios: gravas, conglomerados, arenas y arcillas (Mapa, 2007: 23). Esta dicotomía, junto con la realidad climática anteriormente expuesta, que facilitaría una mayor recarga por lluvia, justificaría el protagonismo que adquieren las fuentes, manantiales y acuíferos en el norte de la provincia, perdiendo entidad e importancia hacia el sur.

Los contrastes físico-climáticos entre el norte y sur provincial deben servirnos para contextualizar un Proyecto con evidente dimensión agrarista: "para fertilizar los terrenos" y corregir los desequilibrios hídricos en la provincia de Alicante.

\section{LA RED HIDROGRÁFICA}

La tradicional clasificación de los ríos valencianos entre ríos autóctonos y alóctonos adquiere protagonismo en beneficio de los primeros en la provincia de Alicante. Solo el río Segura, desnaturalizado por los regadíos murcianos, que entra en la provincia de Alicante encajado en la Depresión Prelitoral Murciana, pertenecería a los segundos. Los cursos fluviales incluidos en el territorio objeto de estudio, esto es, "la zona del terreno que se relaciona con el proyecto, tiene por límite oriental el cabo de Toix y la divisoria de los ríos Jalón y Algar; por límite Occidental el campo de Elche; por la parte de Septentrión la divisoria del Serpis con el Callosa, y por Mediodía el mar Mediterráneo" (Morell, 1866: 12), pertenecerían a los primeros: es decir, el sistema formado por los ríos Algar-Callosa-Bolulla, río Torres, Amadorio o río de Villajoyosa, Seco o Monnegre, y una serie de barrancos y ramblas entre los que se destacan el del Amerador y el de las Ovejas, cuenca donde ha de finalizar el Canal después de recorrer 96 kilómetros.

Las características físico-climáticas del territorio alicantino permiten caracterizar estos cursos como de ríos-rambla. El régimen que mejor los define es el de un régimen mediterráneo subtropical, con máximos en las estaciones equinocciales, en especial la otoñal, y un acusado y, en ocasiones, prolongado estiaje veraniego. Todos ellos, al igual que el conjunto de los ríos-rambla del sureste peninsular, mantienen unas características comunes: escasos módulos tanto absolutos como específicos, débil escorrentía superficial y acusada variabilidad anual e interanual. A los no infrecuentes periodos de escasez pluviométrica les suceden copiosos e intensos aguaceros que, sobre las acusadas pendientes de las pequeñas cuencas, ocasionan avenidas acompañadas de un importante acarreo sólido. Así, "las aguas del río Torres son accidentadas casi en su totalidad, debiendo los mayores aumentos de su caudal a los torrentes que se desprenden de las montañas inmediatas (...). Sin embargo de estos riegos pueden utilizarse las [aguas] de invierno y las de avenida que son cuantiosas" (Morell, 1866: 18). Si bien todos estos cursos mantienen unas características comunes, las diferencias pluviométricas entre el norte y el sur de la provincia permiten cierta diferenciación entre los septentrionales y los de la mitad sur. Entre los primeros se encontraría el sistema Algar-Callosa-Bolulla, donde "se hallan las principales aguas, ya por el número de afluentes como por el caudal de que constan", lo que justifica el origen del Canal y el protagonismo que adquiere tal sistema en la alimentación del mismo. Por tal motivo, a continuación llevaremos a cabo una caracterización del 
mismo. Por el contrario, el resto de los cursos descritos por Morell en el Proyecto se incluirían dentro del segundo grupo: río Torres, Amadorio o Monnegre, entre otros.

Figura 2. Mapa de las cuencas hidrográficas por las que discurre el canal del Algar.

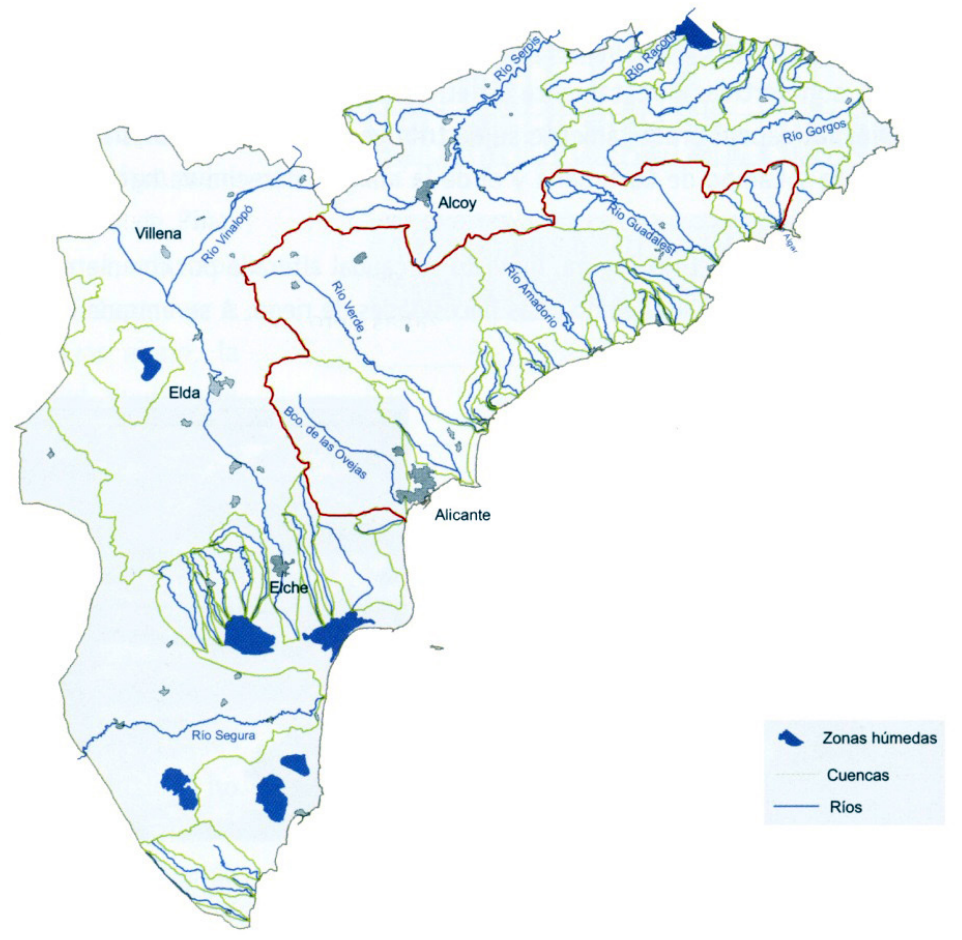

Elaboración propia

En el sector occidental de la sierra de Bernia se localiza el complejo formado por los ríos Algar, Callosa/Guadalest y Bolulla, ocupando una extensión de 212,2 $\mathrm{Km}^{2}$ (sistema fluvial Algar-Guadalest). Emplazado dentro del denominado Prebético Alicantino, dice Morell que "la convergencia de estos ríos dispuesta por la naturaleza, da al terreno sobre el que se asientan los pueblos de Callosa de Ensarriá, Chirles, Polop, Nucía, Alfaz y Altea, un aspecto de anfiteatro sorprendente, abierto hacia el mar, cuya coronación está formada por las crestas de la sierra de Vernia, de la Peña del Contador, la Chortá y Puigcampana" (Morell, 1866: 12). El complejo se localiza en un sector interior y montañoso, que organiza toda la escorrentía superficial a partir de una densa red de pequeñas cuencas, barrancos y desfiladeros, "prolijo e inútil sería enumerar los cauces atravesados por nuestro estudio" (Morell, 1866: 12), donde se localizan alturas significativas tales como el Puig Campana de $1.410 \mathrm{~m}$. o la Sierra de Bernia, y un sector costero, menos agreste y escarpado, ligeramente alomado y de intensa ocupación antrópica.

Así describe Cavanilles el nacimiento del río Algar:

El Algár nace por dos bocas en la raíz meridional de Bérnia á media hora de Callosa en el distrito dels Sacs: sus aguas son cristalinas, perennes y abundantes, y aumentadas con las de otro riachuelo que baxa de Bolulla corren hasta el mar por un solo cauce con las del Guadalést. Algunos como Escolano llaman río de Altea al que resulta de los tres susodichos, acaso por pasar no léjos de esta villa; pero los naturales lo llaman Algár. Lo cierto es que sus aguas tienen la propiedad de conservarse puras en los viages de mar, y por esto se prefieren á las restantes de la costa.

El río Algar se localiza en la comarca de la Marina Baja y forma, junto con el río Amadorio, uno de los nueve Sistemas de Explotación adscritos a la Demarcación Hidrográfica del Júcar (Torregrosa, 2009: 53). La exposición de su cabecera a los flujos húmedos le permite una importante alimentación pluvial, con valores medios en torno a los $850 \mathrm{~mm}$., y aun, en años húmedos, valores que superan los $1.700 \mathrm{~mm}$. (Marco et al., 1998: 123). Su caudal "perenne y abundante", tal como destaca Cavanilles, se refuerza por las surgencias de las Fuentes del Algar, con caudales de 300 1/seg., confluyendo, aguas abajo, por su margen derecha, con el "riachuelo que baxa de Bolulla". Efectivamente, las aguas que drena esta pequeña cuenca 
tienen su origen en el afloramiento de una serie de manantiales entre los que Morell destaca las "fuentes denominadas Sarocha, Azud y Salt", con caudales que no superan los 50 1/seg., aguas abajo, "la fuente de Mas deslizada en forma de lluvia de las grietas de un enorme peñasco", y, por último, los afloramientos en un desfiladero que son "origen por su pintoresca situación del renombre que toman muchas fuentes que allí nacen, llamadas del Estrecho" (Morell, 1866: 15). Unidos el río Algar y el Bolulla, y hasta la confluencia con el río Callosa aguas abajo, la escorrentía superficial se organiza en esta subcuenca denominada del Alto Algar, con una extensión de $73 \mathrm{~km}^{2}$.

Dice Cavanilles que el río Callosa o de Guadalest "sale de aquel profundo y frondoso sitio describiendo curvas por el sur de Callosa de en Sarriá, y por el norte de Polóp y Lanusiá hasta la confluencia con el llamado Algár, donde pierde el nombre"; es el afluente más importante del Algar y constituye una subcuenca de 112,5 $\mathrm{Km}^{2}$, con una longitud en su cauce de $21 \mathrm{Km}$. "La situación de este río, opuesta a la del Algar, originado en una divisoria de la que parten otros en distintas direcciones" (Morell, 1866: 17), justifica una alimentación pluvial inferior respecto al Algar, registrándose valores medios en torno a los $600 \mathrm{~mm}$. y 1.079 en los años húmedos (Marco et al., 1998: 123).

Regulado en cabecera por el pantano de Guadalest, discurre paralelo a la sierra de Aixorta. Morell destaca en su alimentación la gran cantidad de afloramientos subterráneos:

En diferentes puntos de su cuenca se hallan distribuidos veinte y nueve manantiales, muchos de ellos abundantísimos y que jamás se han visto secos, a los cuales denominaremos constantes y otros que suelen perder sus aguas por el mes de Agosto ciertos años, o llevan en su corriente una cantidad insignificante, y los denominaremos variables porque sufren alteración en su caudal a cualquier accidente (1866: 16).

El protagonismo que adquiere la alimentación subterránea a los caudales del río Callosa o río de Guadalest se justifica por la pertenencia de parte de esta subcuenca a una de las principales unidades hidrogeológicas de la provincia de Alicante, como es la de la sierra de Aitana. En cabecera, son estos aportes subterráneos los que, junto con la escorrentía superficial, alimentan el pantano de Guadalest $\left(16 \mathrm{Hm}^{3}\right)$. Aguas abajo del pantano, el río mantiene su caudal ecológico y recibe la escorrentía superficial de los sectores orientales de la sierra de Aitana. Son significativos los flujos que aportan los manantiales del barranco próximo al municipio de Chirles, "de corta extensión, por prestar sus aguas al río Callosa a los 2.130 metros de su nacimiento" (Morell, 1866: 17).

A escasos $4 \mathrm{~km}$ de su desembocadura el Algar confluye con el río Guadalest y forman la subcuenca del Bajo Algar con una extensión de $19 \mathrm{~km}^{2}$. En dicho tramo, es hegemónica la ocupación del territorio de dimensión urbano-turística y se complementa con usos agrícolas en los que el regadío adquiere protagonismo. Sin embargo, ello no impide que aún el río vierta agua en su desembocadura al norte del municipio de Altea.

\section{ALICANTE: UN CONTEXTO SOCIAL Y ECONÓMICO FAVORABLE AL PROYECTO DEL CANAL DEL ALGAR}

No es un acontecimiento fortuito que en 1866 vea la luz en Alicante el Proyecto del Canal del Algar del arquitecto Francisco Morell y Gómez. Desde mediados del siglo XIX, tanto en la capital como en su entorno agrícola productivo, la Huerta, se va gestando un contexto social y económico favorable tanto al incremento como a la búsqueda de nuevos caudales (Cabrera et al., 1999: 107-122): el crecimiento demográfico, un agrarismo de base burguesa o el creciente protagonismo económico del puerto serán, entre otras, algunas de las razones.

El Proyecto nace, así, favorecido por un contexto social y económico a actuaciones de estas características y sustentado bajo los planteamientos de un incipiente regeneracionismo, si bien su fecha de aparición, es, aún, temprana.

La peculiaridad que la revolución liberal adquirió en España habría permitido que amplios sectores de la nobleza encontraran en las formas del capitalismo una manera de mantener su estatus económico y en las propuestas del moderantismo su pervivencia en los grupos de poder político. En Alicante, una nobleza reconvertida al capitalismo de base agraria forma, junto con la incipiente burguesía comercial, de negocios o terrateniente, una oligarquía política, social y económica. Entre las rentas más altas de la provincia se encontrarían estas dos realidades sociales, que habrían encontrado en la tierra un nexo co- 
mún para, a partir de las nuevas formas jurídicas del liberalismo, incrementar y desarrollar sus rentas. El conde de Casas-Rojas, el barón de Finestrat, el marqués de Algorfa, el conde de Santa Clara, la condesa de Almodóvar... serían representativos de los primeros, mientras que los herederos del marqués de Bonanza, Guillermo Guzmán, Mariano Oriente y Antonio Campos y Gil, entre otros, representarían a esa incipiente burguesía. Madoz lo destaca al afirmar que "[e]n ningún punto de España se encuentra un cultivo más esmerado que en la provincia de Alicante, ni mayor variedad de producciones comparables por lo delicado y fino de su gusto a los mejores que rinden los suelos destinados con especialidad a cada una" (Madoz, 1865: 623).

Será, pues, para Morell, "en un país de tales condiciones, la cuestión de aguas" (Morell, 1866: 6) el problema más importante al que debería enfrentarse esta oligarquía vinculada a la tierra para mantener su dinamismo económico junto con un numeroso grupo de pequeños propietarios distribuidos por las partidas del agro alicantino. Así, Juan Roca de Togores, en su Memoria sobre el estado de la agricultura en la provincia de Alicante de 1849 , afirma que

[s]iendo los generadores de la vegetación el calor y humedad, y gozando Alicante de un hermoso clima y de una temperatura elevada, falta tan solo suplir a la escasez de lluvias, que parece rehusarle la conformación del terreno, con los riegos (Vidal, 1986: 123).

Y aún Madoz destaca que

[m]ás abundantes de lo que en el día son, y si es posible más variadas serían las producciones, si los alicantinos pudieran conseguir alguna parte de las aguas del Júcar; en este caso la provincia de Alicante nada tendría que envidiar ni a la Italia ni a la Grecia (1865: 623).

Años más tarde, en 1875, Augusto Echevarría, ingeniero secretario de la Junta de Agricultura, Industria y Comercio, insiste en esta cuestión al redactar su Memoria sobre el estado de la agricultura en la provincia de Alicante:

El amor que profeso a mi carrera y el deseo de que en España en general y en esta provincia en particular llegue a la altura que merece el desarrollo de la nobilísima ciencia agrícola frente a todo género de prosperidades, conducida por sabios preceptos, por paternal y justa protección, de quien nadie es más digno que el agricultor alicantino por los escasos medios que la naturaleza concedió a algunas comarcas de la provincia y que sería de desear se las proporcionara el arte llevado a un grado de perfección tal como es preciso para suplir las faltas de vías de agua y otros de no menos importancia (Vidal, 1986: 199).

Estas élites económicas y sociales serán las que, desde mediados del siglo XIX, plantean en Alicante propuestas de crecimiento económico de corte agrarista, y, desde diferentes organismos, que ellos mismos controlan, llevar a cabo campañas en defensa de sus intereses (Díaz, 2009: 151). Es el caso de La Compañía Alicantina de Fomento, que, desde 1846, y a través del semanario El Mensajero, llevó a cabo campañas en "beneficio de la agricultura, comercio, navegación e industria" (El Mensajero, ${ }^{\circ}$ 31); algunos de los propietarios agrícolas formaban parte de la Junta de Gobierno de la Compañía, y el citado semanario se convirtió en todo un recetario "en beneficio de la ciencia agrícola" (El Mensajero, $\mathrm{n}^{\mathrm{o}} 41$ ): defensa de los nuevos cultivos, importancia del riego y de la necesidad de la traída de aguas, de la creación de escuelas agrícolas, ventajas de los abonos, etc.

De este modo, las propuestas económicas más genuinas del regeneracionismo, como son el agrarismo y el fomento del regadío a partir de una política hidráulica de fomento de las obras hidráulicas, encuentran en Alicante un contexto favorable para su arraigo temprano. En el mismo semanario se afirmaba que "una de las más marcadas ventajas que llevan a los canales es la de estar al abrigo de todas las irregularidades de circulación, y de todos los inconvenientes que ofrecen las influencias atmosféricas (El Mensajero, $\mathrm{n}^{\mathrm{o}}$ 58); y "las tierras procedentes de los pozos, canales, estanques o pantanos, convenientemente enjutas y mezcladas, son las más preciosas materias de que en agricultura se puede disponer" (El Mensajero, $\mathrm{n}^{\circ}$ 64). Subyace, pues, en el desarrollo del Proyecto del Canal de riego del arquitecto Francisco Morell, una ideología de filiación regeneracionista, de "acción regeneradora" (Morell, 1866: 102); se busca, en definitiva, "[f] undar con seguridad la obra de regeneración del de estas hermosas huertas" (Morell, 1866: 48). Así, los planteamientos de crecimiento económico esbozados por el autor del Proyecto pasan necesariamente por el "aumento de la producción y del vigoroso desarrollo de la actividad que ha de producir la canalización de nuestras corrientes", puesto que "en empresas de esta índole, pues, cifra hoy todo su porvenir España" (Morell, 1866: 10). Son, en ese sentido, significativas las palabras con las que concluye la justificación del Proyecto: 
Ojalá también que España entera se persuada de que su porvenir depende hoy de empresas de este género, y que todos, todos, apliquemos nuestra actividad y nuestros esfuerzos a realizarlas, puesto que solo ellas, desenvolviendo los gérmenes de vida que encierra nuestro suelo, podrán sacarnos de la postración que nos agobia y llevar a término la regeneración a que aspiran los verdaderos amantes del país (Morell, 1866: 104).

Las sequías han servido históricamente de acicate y estímulo para desarrollar una serie de iniciativas tendentes a combatirlas y aun erradicarlas, entre ellas, las obras hidráulicas (Gil, 2001: 169). Estas, que "se han manifestado periódicamente con mayor o menor intensidad y siempre seguidas de sus naturales y desastrosas consecuencias" (Morell, 1866: 5), son argumento permanente al que hace referencia el autor cuando quiere justificar la viabilidad del Proyecto:

Que el canal proyectado es una necesidad imperiosa para el país que está destinado a fertilizar, y el único elemento capaz de conjurar la decadencia que se dibuja ya en el horizonte de Alicante, así como el único remedio posible para curar los males que afligen a estas comarcas, las sequías que las consumen, la escasez que las empobrece, las emigraciones que las despueblan y las contrariedades, en fin que se oponen al desarrollo de su riqueza y mejoramiento material y social (Morell, 1866: 103).

Sin duda debió de ser la sequía de 1846-50 en Alicante la que generó un consenso general hacia la solución del problema:

La persistencia de esta última sequía [1846-50] concluyó por aniquilar los viñedos, cuyos productos, que habían dado una reputación envidiable al país en los mercados extranjeros, constituía un ramo importantísimo de riqueza pública; destruyó el arbolado, redujo a la miseria a las casas más antiguas y más importantes por la extensión de su propiedad territorial, sobre la que se fundaban muchos títulos nobiliarios y por último, produjo con una espantosa miseria, la falta casi absoluta del pago de los impuestos públicos y una emigración, cuyas proporciones fijaron seriamente la atención del Gobierno (Morell, 1866: 6).

De la severidad de la misma también se había hecho eco, en 1849, Juan Roca de Togores:

Han disminuido de tal modo las lluvias y consiguientemente los manantiales y arroyos, que la sequía no solo se hace sentir a los campos, haciendo su cultivo improductivo, sino que también ha llegado a faltar el agua a los mismos habitantes, y en la huerta de Alicante se han visto por ella precisados aquellos industriosos trabajadores a abandonar su país, quedando pueblos enteros, entre otros los de Santa Faz, San Juan, Benimagrell y Palamó (Vidal, 1986: 100).

Sería, pues, "el deseo de hallar los medios de satisfacer la imperiosa necesidad que ocasiona la carencia de aguas" (Morell, 1866: 6), junto con ese contexto socio-económico favorable, lo que impulsaría al prócer local D. Blas de Loma y Corradi, destacado personaje de la cultura alicantina de la segunda mitad del siglo XIX, y que aparece como concesionario de las obras, a iniciar los trámites para la construcción de un canal que, derivando las aguas de los ríos Algar, Bolulla y Callosa, tratara de corregir la penuria hídrica de las comarcas de la Marina Baja (Callosa de Ensarriá, Altea, Polop, La Nucía, Alfaz del Pi, Benidorm y Villajoyosa), Campo de Alicante (Campello, San Juan, Muchamiel, Villafranqueza y Alicante) y Bajo Segura (Elche), con usos preferentemente agrícolas.

\section{EL PROYECTO DEL CANAL DEL ALGAR DE FRANCISCO MORELL Y GÓMEZ}

En 1866, cuando el sistema político isabelino agoniza, aparece en Alicante el Proyecto de Canal de riego para fertilizar los terrenos de los términos de Callosa de Ensarriá, Altea, Polop, Nucía, Alfaz, Benidorm, Villajoyosa, Campello, San Juan, Muchamiel, Villafranqueza, Alicante y Elche, del arquitecto valenciano Francisco Morell y Gómez.

El Proyecto ve la luz en los comienzos de uno de los periodos más interesantes y fructíferos para la historia de la hidráulica española; cuando, abandonados los infortunios de la primera mitad de siglo, y paralelamente al desarrollo de un estado liberal, va tomando cuerpo una verdadera política hidráulica. Prueba de ello será la prolífica legislación en materia de aguas, los avances en el campo de las obras públicas, la creación de organismos e instituciones encargadas de la planificación hidrológica y del conocimiento de los cursos fluviales y, lo que es más importante, la gestación de una conciencia nacional de que estas cuestiones deben ser la base sobre las que descanse el progreso y el desarrollo de la nación.

Iniciados los trámites en 1862, momento en el que el Ministerio de Fomento autorizó los estudios, vio la luz definitivamente en 1866, año de la promulgación de la Ley de Aguas, a la que tuvo que adap- 
tarse (Bru, 1984:320). El Proyecto intenta paliar la histórica carencia hídrica de las tierras alicantinas, cuando el Estado liberal destina una atención preferente a la cohesión del territorio con protagonismo del ferrocarril -que recibió importantes subvenciones-, lo que provocó que fuera la iniciativa privada la encargada de la construcción de las obras hidráulicas. Tal sería el caso del proyectado Canal del Algar.

Figura 3. Plano general del canal del Algar y trazado por dónde discurre

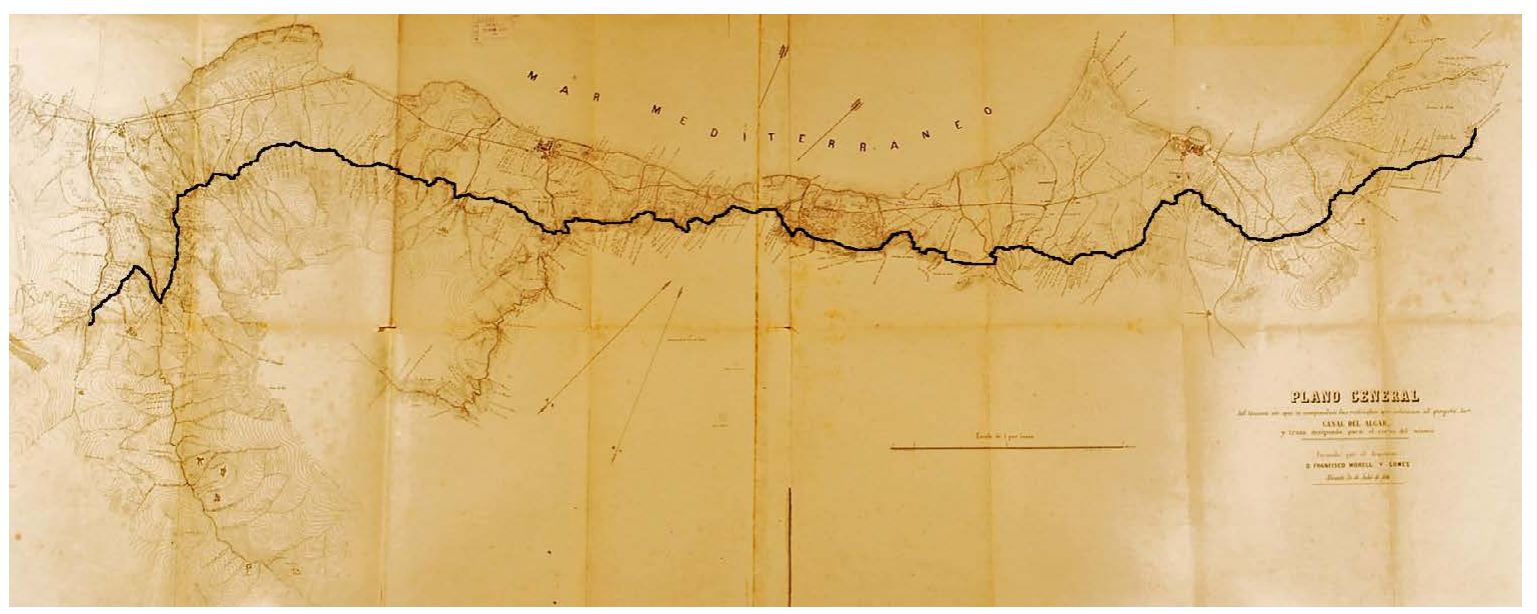

En este apartado vamos a tratar de justificar el porqué consideramos al Proyecto del Algar como "proyecto temprano del regeneracionismo hidráulico". En los argumentos y justificaciones que el autor defiende en su Memoria del Proyecto para que este pueda ejecutarse están, a mi entender, algunos de los planteamientos económicos más genuinos del movimiento regeneracionista, como son el agrarismo y la política hidráulica. Dos cuestiones que algunos de los defensores del movimiento regeneracionista se encargaron de difundir a través de organismos e instituciones, conferencias, libros o artículos de prensa, entre otros muchos medios. Recordemos que las ideas vinculadas a la regeneración aflorarán tras la crisis del sexenio revolucionario (1868-1874), que encontrarán un amplio respaldo a partir de la década del ochenta y las dos primeras décadas del siglo XX, y que, progresivamente, se irán diluyendo hasta los años treinta.

\subsection{El medio físico como obstáculo: el secular combate contra la sequía}

Uno de los planteamientos más generalizados por parte de los regeneracionistas es que las "limitaciones ambientales" son la causa de los Males de la Patria, en especial, la escasez de lluvias. Para Lucas Mallada, el "clima de España es extraordinariamente seco" (Mallada, 1882: 87), y Costa afirmaba en 1900 que "la desgracia de España ha nacido principalmente de que no llegó a entrar en la conciencia nacional la idea de que la guerra interior contra la sequía (...) tenía una importancia mayor que la guerra contra el separatismo cubano y filipino" (Gómez Mendoza, 1992: 233).

Así, entre las principales justificaciones del Proyecto se encuentra "la sequía periódica y la general escasez de lluvias de esta región" (Morell, 1866: 5), unas sequías que, efectivamente, periódicamente afectan a Alicante y que "se oponen al desarrollo de su riqueza y su mejoramiento material y social" (Morell, 1866: 103). Son, pues, constantes las referencias que lleva a cabo el autor a sus "desastrosas consecuencias": "Hubiera sido un verdadero paraíso [Alicante] si las proverbiales sequías de su territorio que los romanos llamaron espartario, no hubieran opuesto constantemente un obstáculo insuperable al completo desarrollo de su agricultura" (Morell, 1866: 5).

Como contrapartida a estos males existe, en el regeneracionismo, un optimismo geográfico que defiende que es posible la solución a tantas desdichas físicas y climáticas movilizando los recursos de la naturaleza. Así, el conocimiento del territorio y de la geografía del país se convierte en una de las propuestas de regeneración, y la corrección hidrológica mediante un sistema de canales de riego y pantanos se plantea como la solución para "crear naturaleza" (Gómez Mendoza, 1992: 241). Estas ideas, esencia de la propuesta de regeneración económica, fueron apuntadas por Costa y encontraron un amplio eco en el periodo entre siglos. 
Un planteamiento de similares características lleva a cabo el autor del Proyecto al detallar la "Descripción geográfica del terreno y de las cuencas comprendidas en él" (Morell, 1866: 11) que se incluye en la redacción de la Memoria. Solo es posible la regeneración mediante el conocimiento de la geografía del país, puesto que "el agua en el seno de la tierra (...) crea, en fin, la riqueza agrícola" (Morell, 1866: 20). Así se entiende que, por Real Orden de 29 de julio de 1865, se crearan las Divisiones Hidrológicas y tuvieran, entre sus objetivos, "dar nuevo y vigoroso impulso a los estudios hidrológicos del territorio de la Península que tanto han de contribuir al fomento de la agricultura y demás industrias", puesto que "la planificación hidráulica se consideraba un instrumento de modernización económica" (Mateu, 1995: 70).

Hay que conocer, en consecuencia, la disponibilidad de los recursos hídricos del territorio, pues "las aguas no pueden humedecer las paredes del canal sino buscándolas en los manantiales, en los ríos, en las vertientes", solo así será posible que el agua "extienda su acción fertilizadora a toda ella con un buen sistema de conducción, a cuya necesidad subvienen los canales que reconocen por el contrario tan importante objeto" (Morell, 1866: 21). Así, un optimismo geográfico recorre todo el Proyecto y nos permite comprender la solución que plantea para la provincia de Alicante: una propuesta técnica, articulada a partir de una obra hidráulica, un canal de riego que "resuelve el gran problema de este país" y que estará destinado a "fertilizar varios términos, a cambiar las condiciones de cultivo, a convertir en fecundamente productores territorios estensos no menos que inútiles" (Morell, 1866: 9). Resulta significativo que su propuesta hidráulica quiera hacerla extensiva al conjunto del país, cuando, aún en 1865, están lejos de aparecer los planteamientos de una política hidráulica como instrumento de modernización agraria y, por extensión, de crecimiento económico:

Si en las empresas de esta índole, pues, cifra hoy todo su porvenir España, si todos los ojos se vuelven hacia ellas como el agente poderoso e indispensable para desenvolver esos gérmenes de riqueza que entraña el suelo y que solo existen latentes e infecundos, si la vida de los ferrocarriles, el equilibrio de nuestra balanza comercial, la consolidación permanente del crédito y de nuestra existencia económica, dependen del aumento de la producción y del vigoroso desarrollo de la actividad que ha de producir la canalización de nuestras corrientes, pocas presentarán mayores consecuencias en este sentido que la que nos ocupa, por las condiciones especiales de la localidad a que se destina (Morell, 1866: 10).

\subsection{Cuestión social, población y regadío}

\section{Afirma Morell que el Canal del Algar}

[e]s el único elemento capaz de conjurar la decadencia que se dibuja ya en el horizonte de Alicante, así como el único remedio posible para curar radicalmente los males que afligen a estas comarcas (...) y las contrariedades, en fin que se oponen al desarrollo de su riqueza y su mejoramiento natural y social (Morell, 1866: 103).

Uno de los aspectos más destacados de las propuestas agraristas del regeneracionismo es la cuestión social en relación con el regadío. Las críticas a la situación del campesinado, especialmente tras la Desamortización, junto con las virtualidades asociadas al regadío, le permitieron a Joaquín Costa (1846-1911) articular una verdadera "reforma social agraria" (Gómez, 2012: 20). También los Congresos Nacionales de Regadío (CNR), continuadores del legado de Costa, e impregnados de verborrea regeneracionista, abordaron la problemática de la mejora de las condiciones del campesinado en algunas de sus ponencias: la colonización de nuevas tierras, fijar la población rural conteniendo la emigración, evitando, así, el éxodo rural; la cuestión ampliamente debatida de la propiedad y el regadío, e incluso virtudes de índole moral en relación con el regadío, como es la felicidad. Sobre esta cuestión se pronunciaba el Presidente de la República, Alcalá Zamora, en la sesión inaugural del V CNR celebrado en Valladolid en 1934, cuando afirmaba que "[s]abe ser el regadío una fuente de riqueza que aplaca la sed de la justicia social en medio de la tristeza de los campos".

El flujo migratorio del campesinado alicantino hacia el norte de África, especialmente hacia Argelia, había sido una constante desde comienzos del siglo XIX, y así lo constata Morell cuando afirma que "ha existido en este país una emigración de considerable número de sus moradores a las colonias francesas" (Morell, 1866: 92). La emigración, sujeta a coyunturas económicas, era intensa en los momentos de crisis agrícolas como la sequía de 1846-50, "cuyo doloroso recuerdo se conserva vivo aún en la memoria de los habitantes del país y cuyas huellas no se han borrado todavía de los campos comarcanos" (Morell, 1866: 6). 
En el proyecto se afirma que las sequías han provocado "miserias y emigraciones" (Morell, 1866: 5), y considera, entre los beneficios que ha de aportar el canal de riego en las comarcas alicantinas beneficiadas por el agua, contener "las emigraciones que las despueblan" (Morell, 1866:103). Existe, pues, entre sus objetivos, uno de carácter poblacional y demográfico, como es el de fijar la población y evitar el despoblamiento rural. No es esta una cuestión menor. En las fechas en las que aparece el Proyecto, nos encontramos en un periodo de apogeo del fomento del poblamiento rural influido por la obra Memoria sobre el fomento de la población rural, aparecida en 1863, de Fermín Caballero (López, 2003:169). Posteriormente, siguiendo el legado de Costa, los CNR abordarán en varias ponencias y comunicaciones esta cuestión, vinculando ya la política hidráulica al regadío y la colonización. En una de estas comunicaciones, Proposición de Ley sobre auxilio del estado a obras hidráulicas, el representante de la Cámara Agrícola de Alicante afirma, en el I CNR celebrado en 1913 en Zaragoza, que la intensificación agrícola, gracias a la canalización de las aguas, ha de servir para, entre otras cuestiones, "deponer nuestra pasividad ante la despoblación de nuestra patria" (1914: 124).

La dimensión social del Proyecto está también presente en la crítica que Morell realiza de los sistemas de riego de "los pueblos de Alfaz, Nucía, Polop, Benidorm y parte de Altea", de Villajoyosa y de la Huerta de Alicante; a todos les atribuye "defectos gravísimos", ya que el agricultor "se entrega a merced de los explotadores del agua" (Morell, 1866: 8) y que es víctima de todos los abusos e inmoralidades que surgen siempre de ciertas situaciones: "El agua es objeto de agiotajes y abusos que redundan en perjuicio de los regantes" (Morell, 1866: 80).

Especialmente crítico se muestra el autor del Proyecto con el sistema de riego de la Huerta de Alicante, "en el que precisamente por la mayor escasez de agua y el mayor valor e importancia que esta escasez da a la existente, son más numerosos los abusos e infinitamente mayores los defectos del sistema y en la práctica administrativa, encaminados siempre a beneficiar a unos cuantos privilegiados con perjuicio de los intereses de la generalidad"; considera "perjudicial en sumo grado a los intereses y desenvolvimiento de la agricultura" que "la mitad del agua destinada a los riegos constituye una propiedad independiente de la tierra", siendo esta la principal causa de que "el pobre agricultor, el cual casi siempre se ve obligado a satisfacer crecidos precios por el agua" (Morell, 1866: 72-74). Concluye afirmando que

[e]l sistema de riegos de Alicante, atendida la frecuente escasez de aguas, se convierte muchas veces en irregular, abusivo, injusto y oneroso para la gran masa de agricultores que apenas pueden hallar compensación a los sacrificios que les impone la necesidad de regar (Morell, 1866: 80).

El detallado estudio que Morell realiza de la evolución de los precios del agua en la Huerta de Alicante entre 1860-1865 le sirve para constatar "la dificultad de fijar términos exactos en este punto, tratándose de sistemas de riego tan irregulares" (Morell, 1866: 79). Así pues, para el autor del Proyecto, con el incremento de los caudales que aportará el canal, se mejorarán "extraordinariamente los sistemas de riego de todas las comarcas que el canal recorre, disminuyendo en inmensa proporción el coste de aquel" (Morell, 1866: 103), y se evitarán, así, aquellas "prácticas viciosas" (Morell, 1866: 70) y abusivas para la inmensa mayoría de los regantes, como es el excesivo precio por el agua. Hay, en consecuencia, una evidente vocación de mejora de las condiciones económicas y sociales de los agricultores.

El paradigma hidráulico que años más tarde enunciará Costa, "rehacer la geografía de la patria para resolver la cuestión política y la cuestión social", vinculando obras hidráulicas, regadío y cuestión social, está ya presente en el proyecto del Canal del Algar, puesto que "el labrador que siente el peso de tanta desdicha, ¿no ha de resumir todas sus aspiraciones y sus esperanzas en esa corriente bendecida que espera siempre inútilmente y que considera con razón como el remedio de todos sus males?" (Morell, 1866: 8).

\subsection{Bienestar, patriotismo y regadíos}

Una cuestión singular relacionada con el regadío y de la que encontramos numerosos ejemplos en la retórica utópica regeneracionista de los CNR es la de atribuirle, más allá de los beneficios económicos, virtudes de índole moral. Así, el regadío, germen de progreso y riqueza, tiene, además, la capacidad de despertar y cultivar cualidades virtuosas tales como el bienestar, el amor al trabajo y hasta la felicidad. "Yo me acuerdo de muchos de los labriegos españoles que llevaron la felicidad a sus hogares" (1922-23: 65), afirmaba el ministro Gasset en la sesión inaugural del III CNR celebrado en Valencia en 1921, recordando la inauguración del pantano de la Peña. 
Impulsarán por mil medios no previstos la actividad y el trabajo, fuentes bendecidas de toda moralidad y bienestar del hombre, y manantial inagotable de la riqueza y engrandecimiento de los pueblos (Morell, 1866: 102).

Sin duda, estas palabras de Francisco Morell en su Proyecto, con relación a los beneficios que sobre las manufacturas locales iba a tener el cambio de cultivos con la llegada de aguas del canal, anticipan muchos de los discursos que, bajo esa misma perspectiva, se pronunciarán a partir de que, en 1913, y en Zaragoza, se celebrase el I de los CNR; así, en 1921, en el III de los CNR, celebrado en Valencia, Gómez González, al referirse a los regadíos valencianos, afirmaba que "los desposorios del agua y la tierra trajeron la riqueza y el bienestar", y que "el cariño que los agricultores sienten por el terruño que cultivan, del que no se apartan porque le da trabajo constante, pan seguro, alegría y libertad" (López, 2001: 14); y Benaiges afirma que la presencia del agua significa para la agricultura y la población "bienestar y prosperidad" (López, 2001: 13).

Y aún en la clausura del V CNR, celebrado en Valladolid en 1934, el Ministro de Obras Públicas, Guerra del Río:

Yo veo en el regadío el aumento de nuestra población campesina y su transformación material y espiritual (López, 2001: 15).

También, y como herederos del legado de Costa, en numerosos de los discursos, ponencias, debates y conclusiones de los diferentes CNR, subyace la idea del fomento del regadío con finalidad y salvación patriótica como una de las bases económicas de la regeneración de la patria. Así se refiere el ministro Gasset (1921: 74) en la sesión inaugural del III CNR celebrado en Valencia:

Por estos procedimientos [los riegos] no se ensanchará el mapa, pero se ensanchará la Patria. (...) Yo os digo que la victoria supone, representa el porvenir, la prosperidad de España.

O en la Convocatoria del IV Congreso de Barcelona, en 1927, cuando se afirma que

[f] ue necesario comenzar por defender el establecimiento de nuevos regadíos, como medio de crear riqueza y contribuir al engrandecimiento nacional (1927: 15).

Y, en 1934, cuando en la sesión de apertura al V CNR celebrado en Valladolid, el Presidente de la República, Alcalá Zamora, se manifestaba en estos términos:

¿Qué significa un propósito de regadío? Un empeño más por la grandeza y para el bienestar de España (1934: 45).

También, y en relación con la labor de los congresistas, es frecuente encontrar discursos en esa línea retórica: "Vuestra labor de hoy tiene de altruista lo que tiene de patriótica"; "vosotros os reunís para pedir algo beneficioso para el país entero" (Gasset, 1921: 62-63), o "la labor hoy iniciada redundará en prosperidad del agro español y de la patria toda" (1927: 29); y, al referirse a la tarea que han venido desempeñando los distintos CNR celebrados hasta 1927, se dice que han servido para "desenvolver más y mejor la riqueza agrícola de la patria" (1927: 31).

Así fue como la tan ansiada regeneración de fundamentos económicos fisiocráticos caló en las conciencias de los elementos encargados de regenerar la nación, que pensaron que estaban ante un momento histórico en el que el regadío había de convertirse en "salvación de la patria".

En semejantes términos se expresaba Francisco Morell en 1866 cuando afirmaba, con relación al canal de riego del río Algar:

Ojalá también que España entera se persuada de que su porvenir depende hoy de empresas de este género, y que todos, todos, apliquemos nuestra actividad y nuestros esfuerzos a realizarlas, puesto que solo ellas, desenvolviendo los gérmenes de vida de nuestro suelo, podrán sacarnos de la postración que nos agobia y llevar a término la regeneración a que aspiran los verdaderos amantes del país (1866: 104). Es, sin duda, la idea del canal del Algar como obra patriótica.

\subsection{Mejora de la riqueza pública, y progreso económico general}

Las propuestas económicas de regeneración no se limitaron al fomento del regadío, incremento de la superficie irrigada y, por extensión, mejora de la agricultura. Si bien es cierto que el agrarismo que se plantea en torno a la política hidráulica está en la base de la regeneración económica, en torno a dicha política se articula todo un programa económico que tenía por objetivo final el incremento de la rique- 
za, en definitiva, el progreso económico del país: "Ahí tiene usted lo que es la 'política hidráulica', una expresión sublimada de la 'política agraria', y generalizando más, de la 'política económica' de la Nación" (Costa, 1911: 300).

Si Morell, en su Proyecto, se refiere al agua como el "agente poderoso e indispensable para desenvolver los gérmenes de riqueza que entraña el suelo" (Morell, 1866: 10), en términos similares se pronunciará Tomás Costa en 1913 en una comunicación presentada al I CNR:

¿No conviene volver la vista hoy, hacia la fuente única de toda riqueza, hacia los suelos para poder aumentar su fecundidad (...)? (Costa, 1913: 7).

O en la ponencia de Antonio Lasierra (1913: 8), cuando afirma que

[h]abremos de convenir que en España, se impone una política económica que mire con singular predilección la agricultura y la minería, porque ambas constituyen la base principal de nuestra riqueza.

Y más rotundo se muestra Gómez González (1921: 21), que, junto con la colonización de las tierras de regadío, "reclama el bienestar público, el fomento de la riqueza agrícola, la paz social y los más primordiales intereses de la Economía Española".

La propuesta económica de regeneración incluía, pues, el fomento y el desarrollo de otras actividades tales como el comercio, los transportes, industrias auxiliares, además del incremento de los valores de propiedad y la contribución territorial.

Así, en su obra La fórmula de la agricultura española, Joaquín Costa (1911: 154) afirma:

¿Quién tiene la posibilidad y sobre quién pesa, por tanto, la responsabilidad y el compromiso de acrecentar rápidamente el comercio de exportación y de sentar sólidamente las bases de nuestra regeneración y de nuestro porvenir? ¿Será la industria fabril y manufacturera? Ya lo habéis contestado vosotros, no. Es la agricultura.

Es la misma dimensión económica que le da Francisco Morell a su Proyecto de canalización de las aguas del Algar:

Esos nuevos elementos de vida de que nuestra empresa dotará estas comarcas, transformando completamente las condiciones actuales del territorio, ofreciendo nuevas aplicaciones al trabajo y actividad de los pueblos y creando múltiples y variadas relaciones comerciales e industriales, asegurarán el bienestar y la prosperidad del país (Morell, 1866: 104).

Y cuyos "enormes beneficios" provocarán

[e]l equilibrio de nuestra balanza comercial, la consolidación permanente del crédito y de nuestra existencia económica, dependen del aumento de producción y del vigoroso desarrollo de la actividad que ha de producir la canalización de nuestras corrientes (...) (Morell, 1866: 10).

Esta proyección económica del regadío más allá del fomento de la agricultura encontrará respuesta, una vez más, en algunas de las ponencias y comunicaciones de los diferentes CNR. Así, Carlos Cardenal (1913: 18) afirma que "dos elementos pueden dar idea de la riqueza de una comarca agrícola: el valor de la tierra y el movimiento de viajeros y mercancías"; y el ingeniero agrónomo Carmelo Benaiges (1913: 48), al referirse a los beneficios que sobre las comarcas ha provocado el Canal de Aragón, dice que está "el mayor tráfico en todas sus líneas de comunicación, cuyos almacenes tienen que multiplicarse ante el creciente movimiento de mercancías (...), por la implantación de nuevas industrias (...) unido al considerable aumento experimentado en el valor de las tierras que preparadas para el riego (...)".

Pero, sin duda, es la comunicación presentada por la Cámara Agrícola de Alicante (1913: 121-137) la que mejor representa, a mi entender, el progreso económico que se puede lograr con la canalización de las corrientes y la extensión de los riegos. La comunicación es todo un argumentario de cómo lograr una superioridad económica frente a las potencias del momento teniendo como base el incremento de los regadíos:

Si con regar tres millones de hectáreas, aumentamos nuestra riqueza agrícola por cima de quince mil millones de pesetas, con la creación de aquella fuerza tendríamos la base de nuestra preponderancia industrial sobre Francia, Alemania e Inglaterra, que hoy se disputan el dominio industrial y comercial del mundo (1913: 125).

El representante de la Cámara Agrícola de Alicante, Francisco Mira Seller, aspira a lograr la superioridad industrial: 
Nosotros, con la canalización de nuestros ríos, conseguiremos producir una fuerza poco menos que gratuita, base de futuras industrias (1913: 126).

Algo que también quiere conseguir con la intensificación de los cultivos industriales:

En materias textiles tales como el esparto, pita y otras, se producirá tan abundantemente como se desee en el Sur y Levante de España, sin recurrir a tantas otras materias, susceptibles de producirse también (1913: 126).

Y con el comercio, base de la superioridad y del desarrollo económico:

Estas corrientes comerciales que llamaríamos periesféricas, en la proporción que aumenten han de dar importancia comercial a su centro natural que es España (1913: 126).

Para concluir afirmando que:

Todos estos movimientos económicos ligeramente esbozados aquí, han de ser necesariamente la base de nuestra futura prosperidad (1913: 127).

La consideración del agua como agente económico, siempre presente en las propuestas económicas del regeneracionismo, también se evidencia en algunos de los párrafos con los que Francisco Morell quiere justificar la canalización de las aguas del Algar. La actividad comercial del puerto de Alicante, "uno de los principales puertos del litoral de España" (Morell, 1866: 10), será una de las actividades que se desarrollará considerablemente con el aumento de las producciones:

Si la actividad comercial de este puerto es hoy tan importante, a pesar de reducir su movimiento a la importación porque carece de productos para alimentar las exportaciones, fácil es calcular el desarrollo que adquirirá esa actividad, cuando merced al aumento de producción y a la posibilidad de frutos exportables, pueda ofrecer a los buques la facilidad del retorno de que hoy carecen, evitándoles las desventajas de expediciones incompletas, que es precisamente el gran escollo en que se estrella el desenvolvimiento completo y regular de la vida comercial de Alicante.

También la industria:

Las industrias que han de producirse necesariamente siquiera sea solo por de pronto para atender a los aperos de labranza, habitaciones, transportes, construcción de diversos útiles y demás necesidades que crea la estensión y modificaciones del cultivo, darán ocupación y medios de existencia a multitud de familias (...) (Morell, 1866: 102).

La introducción de nuevos cultivos, más rentables, y otros orientados a la industria manufacturera:

El cambio de productos y el cultivo de los que hasta ahora no han podido obtenerse por falta del primer elemento necesario para ello, tales como el cáñamo, el lino, la seda y otros variados, aplicados a la elaboración de paños, sederías, tegidos, lienzos, alfarería y otras manufacturas conocidas por la industria española (Morell, 1866: 102).

Así como la modificación de los valores de propiedad con la transformación de los terrenos secanos en regadíos y del incremento del capital del Estado en concepto de contribución territorial:

Cuando se pueda aplicar con utilidad a los riegos toda la cantidad de agua que el canal arroje, los terrenos secanos que dejarán de serlo, vendrán a igualar su valor en venta y renta con los de regadío, resultando por consecuencia aumentado el capital representado por la propiedad rústica (...) y, por último, los del Estado en concepto de contribución territorial (Morell, 1866: 101).

Esta cuestión estuvo presente en varias ponencias y comunicaciones de los distintos CNR. Afirmaba Lasierra (1913: 4-16):

(...) y acabarán por dedicarse en España al cultivo intensivo algunos millones de hectáreas de terrenos hoy baldíos, aumentando enormemente nuestra riqueza nacional, y de paso las rentas del Estado.

También Prado y Palacio (1918: 376), en el Congreso de Sevilla:

Al estudiar el magno y trascendental problema de la posible transformación de dos millones de ha. de nuestra superficie cultural de secano en regadío (...) con el objetivo de alcanzar el ideal de asegurar el aumento fantástico de riquezas que supone para la economía nacional la diferencia entre los $70 \mathrm{u}$ 80 o 100 pts. que puede rendir la ha de secano a precios normales de producción, a los 400,600, 800 y hasta más de 1.000 pts de la ha. de regadío.

E incluso la citada comunicación de la Cámara Agrícola de Alicante: 
Y acabarán por dedicarse en España al cultivo intensivo algunos millones de ha. de terrenos hoy baldíos, aumentando enormemente nuestra riqueza nacional, y de paso las rentas del Estado en relación a la riqueza creada (1914: 123).

Por último, resulta interesante comprobar cómo el debate que se suscita en 1913 en el marco del I CNR, celebrado en Zaragoza, con relación al sacrificio presupuestario al que debe hacer frente el Estado para la construcción de obras hidráulicas para el fomento de los regadíos cuando los beneficiados son los particulares, sea en el Proyecto del Canal del Algar motivo también de reflexión y análisis por parte del autor, resolviéndose, en 1866, de igual manera que algunos de los autores participantes en el debate congresual:

Cualquiera que sea, pues, la base que para nuestros cálculos adoptemos resultará siempre, por la acción regeneradora de nuestra empresa, un aumento considerable de riqueza pública y privada, y en todos los elementos que constituyen la vida del país (Morell, 1866: 102).

Del mismo modo, A. Lasierra afirmará en 1913 que

[c] oncedido que los propietarios de las tierras ganan mucho con la implantación del regadío, pero concédase a ellos de igual modo, que sus ganancias pueden no ser incompatibles con el interés de la Nación.

Para concluir:

No olvidemos que la riqueza individual es el elemento de la riqueza pública (López, 2001: 10).

\subsection{Higienismo, salubridad y ornato}

Desconocemos la fecha exacta del nacimiento en Valencia del arquitecto Francisco Morell y Gómez. Perteneciente a la última generación de profesionales formados en el seno de la Academia de San Carlos de Valencia en torno a los años cuarenta, desempeñará prácticamente toda su labor profesional en la provincia de Alicante.

Si bien es cierto que su formación es académica y los criterios urbanísticos de racionalidad y regularidad, ordenación y ornato y funcionalidad, así como su adhesión a los principios del clasicismo, estarán siempre presentes en sus diseños residenciales, fue un arquitecto que, superados los criterios academicistas con el avance de la segunda mitad de siglo, fue capaz de adaptarse a las nuevas realidades y problemáticas que plantea la ciudad conforme avanza el proceso de industrialización.

La ciudad se convierte, conforme avanza el siglo XIX, en un espacio cargado de simbolismo. Es el centro de poder económico, político, además de ser el espacio donde reside la nueva clase social surgida tras la disolución del Antiguo Régimen. Sobre este nuevo escenario tratará de desarrollar Morell su labor de proyectista y de arquitecto.

En Alicante, fue Arquitecto Titular en el Ayuntamiento durante el periodo comprendido entre 1854 y 1859, cargo que comparte con José Fuentes.

El modelo de ciudad que, bajo los criterios academicistas, se configura en Alicante entre 1810-1850 en torno al denominado Barrio Nuevo, queda superado a partir de la segunda mitad del siglo XIX, produciéndose la "disolución definitiva de la ciudad académica entre 1859-1870" (Calduch, 1990: 26). Los problemas que empiezan a aflorar con la industrialización y el crecimiento demográfico, tales como la segregación social, los problemas de salubridad e higiene, hacinamiento, movilidad, necesidad de nuevas vías de comunicación (ferrocarril y red de carreteras) y de nuevos espacios productivos y residenciales, etc., están detrás de los proyectos urbanos que por esas fechas preocupan a los arquitectos/urbanistas, encontrándose entre ellos Francisco Morell. Al Plano Geométrico de 1849 del arquitecto Emilio Jover, dentro del paradigma academicista, Morell plantea, en 1856, un plano geométrico nuevo y diferente. Sus proyectos de reformas de esas fechas, años sesenta, se enmarcan dentro de estos nuevos paradigmas urbanos que plantea la ciudad industrial.

En este nuevo escenario de necesidades urbanas, entre ellas la mejora de la salubridad e higiene, y que empiezan a preocupar a las autoridades municipales, se contextualiza la importancia que tiene para Francisco Morell la llegada de "aguas potables" para Alicante:

Impulsados por el estímulo de esa necesidad constante, los ayuntamientos todos que se han sucedido en la dirección de la administración local, no han esquivado gestión ni medio alguno para hallar solución difícil al problema de encontrar manantiales capaces de subvenir al servicio público, pero 
como, por desgracia, sus laudables esfuerzos no han obtenido nunca el éxito apetecido hoy como anteriormente carece la capital de la dotación de agua que requiere una población de su índole, no sólo para el uso ordinario e indispensable a la vida, sino para llenar las prescripciones de una buena higiene urbana y hasta las exigencias de ornato y embellecimiento públicos (Morell, 1866: 81).

Para Morell, la llegada de agua potable a la capital "bastaría por sí sola para decidir a los pueblos a acometer la empresa", puesto que "las aguas potables, son necesidad tan imperiosa y asunto tan importante para la vida de sus localidades, que determina casi siempre la situación de éstas, su bienestar, su engrandecimiento y hasta su mayor o menor grado de cultura". Morell destaca el problema endémico del agua en Alicante, "la escasez y la mala calidad", situación que se agrava durante el estío: "esta penuria que crece en proporciones en la estación estival, ha producido en más de una ocasión serios conflictos a las corporaciones municipales"; o ante eventualidades como los periodos de sequía. Como siempre, los grupos más desfavorecidos eran los que más sufrían las restricciones o la escasez de recursos.

Consciente de que "la necesidad va haciéndose más y más imperiosa, a medida que la población esperimenta el aumento progresivo que es común a todas las comarcas de España" -en 1870 la población se situaba en 21.719 habitantes en el sector urbano, siendo las del municipio 29.550, alcanzando la cifra de 50.142 habitantes al final de la centuria-, lleva a cabo una estimación del consumo de agua (urbano y agrícola) para Alicante, tomando como referencia el "abastecimiento de aguas de Madrid". Debemos destacar que entre los usos domésticos incluye el aseo corporal, cuyo gasto eleva a 10 litros por alma y día, estipulando el consumo para este uso en 300.000 litros. Los otros usos que establece: Alimento del hombre, 2 litros por alma al día (60.000 litros); Alimento de animales, 1 litro por animal y día (30.000 litros); Industrias, 1.050 .000 litros; Riego, 650.000 litros; Fuentes monumentales o de servicio, 120.000 litros y para extinción de incendios, 40.000 litros. El consumo total diario lo establece en consecuencia en $2,250 \mathrm{~m}^{3} /$ día.

A la dimensión económica que tienen de los recursos hídricos para el autor, cabe añadir ahora la importancia social cuando afirma que "los resultados serán dotar de aguas potables a una capital que solo espera ese elemento para desenvolverse y adquirir el grado de embellecimiento, vida, actividad e importancia a que está llamada por su envidiable posición marítima y sus condiciones naturales", que lo vinculan directamente con los planteamientos regeneracionistas que empiezan a aflorar por esas fechas en España: "no necesitamos encarecer los inmensos beneficios que bajo este solo aspecto está destinado a ofrecer a estas comarcas la regeneradora empresa que proyectamos" (Morell, 1866: 84).

\section{CONCLUSIÓN}

La singularidad física y climática de las tierras alicantinas establece significativas diferencias entre las comarcas del norte y sur. La elevada pluviométrica, los abundantes recursos hídricos subterráneos y las características de los ríos de los sectores de la Marina Baja contrastan con la escasez de recursos, en general, de las tierras alicantinas del sur. Establecidos ya en el último tercio del siglo XIX los principios del liberalismo en Alicante, una burguesía agrícola encuentra en la tierra un elemento para incrementar sus rentas y así consolidar su poder económico y político. Este contexto económico y social favorable, junto con adversidades de índole climática como es la sequía de 1846-1850, propiciará la redacción, en 1866, del Proyecto de canal de riego de las aguas del Algar hacia las comarcas del sur, en especial la Huerta de Alicante, del arquitecto valenciano Francisco Morell y Gómez. El objetivo no es otro que combatir uno de los males a los que periódicamente estaba expuesto el agro alicantino, las sequías, y reconvertir la agricultura alicantina en una agricultura intensiva, de regadío, con proyección comercial y exportadora.

No se trata de un Proyecto sin más. Junto al detallado estudio geográfico, técnico y financiero que lleva a cabo el autor (terreno y cuencas por las que ha de discurrir el canal, estudio de aforos, crítica del sistema actual de riegos, cálculos económicos, calidad de las aguas, financiación, obras que se deben realizar, etc.), destacan los argumentos que a lo largo de la Memoria aparecen para justificar y ejecutar el Proyecto. Si bien es cierto que en la fecha de aparición del Proyecto las bases de una política hidráulica están, si acaso, en España insinuadas, en los razonamientos que da el autor para justificar su Proyecto se encuentran muchos de los principios que marcarán el devenir de la política hidráulica española con el advenimiento de los principios del movimiento regeneracionista: los males de la patria personalizados en las sequías, la necesidad de fijar la población a partir del regadío, el desarrollo del comercio, industria, en definitiva, el desarrollo económico, la introducción de nuevos cultivos, las virtualidades asociadas al 
regadío e incluso el papel que debía desempeñar el Estado. Son frecuentes las referencias a la obra proyectada como obra de regeneración.

Diversos acontecimientos técnicos y económicos retrasaron la aprobación del Proyecto. Modificado el trazado original, en 1902 fue incluido en el Plan General de Riego y Pantanos o Plan Gasset y posteriormente también en el Plan General de Obras Hidráulicas de 1933 bajo la denominación de Canal de Eduardo Dato. Pero no llegó a ejecutarse. Hoy, el Canal del Bajo Algar, construido a partir de 1944 dentro del Plan General de Riegos de la Provincia de Alicante, es heredero del Proyecto ideado por Morell y cumple, en gran medida, buena parte de los objetivos previstos por el arquitecto valenciano.

\section{REFERENCIAS}

I Congreso Nacional de Riegos. Celebrado en Zaragoza entre los días 2 y 6 de octubre de 1913. Tipografía de G. Casañal. Zaragoza, 1914. Tomo I: Prólogo. Síntesis de las Conclusiones. Crónica. Comunicaciones. Tomo II: Ponencias.

II Congreso Nacional de Riegos. Celebrado en Sevilla entre los días 5 y 11 de mayo de 1918. Sociedad Española de Artes Gráficas. Madrid, 1919. Tomo I: Prólogo. Crónica. Comunicaciones.

III Congreso Nacional de Riegos. Celebrado en Valencia entre los días 25 de abril y 3 de mayo de 1921. Imprenta Hijo de F. Vives Mora. Valencia, 1922-1923. Tomo I: Crónica. Bibliografía. Información gráfica. Tomo II: Ponencias. Discusiones. Conclusiones.

IV Congreso Nacional de Riegos. Celebrado en Barcelona en mayo y junio de 1927. Imprenta Bayer Hermanos y Cía. Barcelona, 1929. Tomo I: Convocatoria. Cuestionario. Reglamento. Patronato y Comisiones. Tomo II: Ponencias y comunicaciones. Tomo III: Apéndice.

$V$ Congreso Nacional de Riegos y Exposición Aneja. Celebrado en Valladolid entre los días 23 al 30 de septiembre de 1934. Imprenta Castellana. Valladolid, 1935. Tomo I: Antecedentes, Comisión Permanente. Comisión Local. Convocatoria. Cuestionario. Reglamento. Programa y Ponencias.

Benaiges, C. (1913). Utilidad de la obra proyectada para riegos del Alto Aragón con relación al fomento de la Riqueza nacional. Actas I CNR, Tomo I (pp.43-53). Zaragoza.

Bru Ronda, C. (1984). El Canal del Algar: un proyecto revolucionario en los albores del siglo XX. Los recursos del agua. Aprovechamiento y economía en la provincia de Alicante, (pp. 320-323). Alicante: Caja de Ahorros del Mediterráneo.

Cabrera Román, C. y Bru Ronda, C. (1999). La sociedad alicantina en el siglo XIX: el marco socio-económico y las corrientes regeneracionistas de finales de siglo. Aguas de Alicante, (pp. 107-122): Alicante.

Calduch Cervera, J. (1990). La ciudad nueva. La construcción de la ciudad de Alacant en la primera mitad del siglo XIX. Alicante: Patronato Municipal del Quinto Centenario de la Ciudad de Alicante.

Cámara Agrícola de Alicante (1913). Proposición de Ley sobre auxilio del Estado a obras hidráulicas. Actas I CNR, Tomo I, (pp. 121-137). Zaragoza.

Cardenal, C. (1913). Datos referentes a la influencia que ha ejercido la construcción del Canal de Urgel. Actas I CNR, Tomo I (pp. 35-43). Zaragoza.

Cavanilles, A. J. (1795-1797). Observaciones sobre la historia natural, geografía, agricultura, población y frutos del reyno de Valencia, Madrid, Imprenta Real, 2 vols.

Costa, T. (1913). Política Hidráulica. Lo que debería tratarse en un Congreso nacional sobre Riegos en opinión de Joaquín Costa. Actas I CNR, Tomo I, (pp. 1-27). Zaragoza.

Costa, J. (1911). La fórmula de la agricultura española. Cap. VI. Recuperado de http://www.cervantesvirtual. com/obra-visor/la-formula-de-la-agricultura-espanola--0/html/.

Costa, J. (1911). Caracteres de la política hidráulica. Cap. 10. Política Hidráulica (Misión social de los riegos en España). Recuperado de http://www.cervantesvirtual.com/obra-visor/politica-hidraulicamision-social-de-los-riegos-en-espana--0/html/.

Díaz Marín, P. (2009). Actividades y estrategias económicas de la burguesía alicantina en los años cuarenta del siglo XIX. Investigaciones de historia económica, (15), pp. 137-170.

Gil Olcina, A. (2001). Secas históricas en la región climática del Sureste Ibérico. En A. Gil Olcina y A. Morales Gil (Eds), Causas y consecuencias de las sequías, (pp. 161-185). Alicante: Caja de Ahorros del Mediterráneo. 
Gómez Benito, C. (2012). Una introducción al pensamiento reformista de Joaquín Costa. En Institución Fernando el Católico (C.S.I.C.), En torno a Costa, Conferencias de Barcelona. 2010, (pp. 15-25). Zaragoza: Excma. Diputación de Zaragoza.

Gómez González, M. (1921). Colonización de grandes zonas de regadío. Relación entre propietarios y cultivadores. Actas III CNR, Tomo II, (pp. 19-69). Valencia.

Gómez Mendoza, J. (1992). Regeneracionismo y regadíos. En Ministerio de Agricultura Pesca y Alimentación (Ed), Hitos históricos de los regadíos españoles, (pp. 231-262). Madrid.

Lasierra, A. (1913). Mejoras económicas obtenidas por la implantación del regadío; aumento de la riqueza. Actas I CNR, Tomo II, (pp. 4-16). Zaragoza.

López Ontiveros, A. (2001). El regadío, salvación de la patria y fuente de felicidad según los Congresos Nacionales de Riegos (1913-1934). Investigaciones Geográficas, (26), pp. 7-40.

López Ontiveros, A. (2003). Población, poblamiento y regadío según los Congresos Nacionales de Riegos (1913-1934). Papeles de Geografía, (37), pp. 165-178.

Madoz, P. (1845). Diccionario geográfico-estadístico-histórico de España y sus posesiones de ultramar, Tomo I, Madrid.

Mallada, L. (1882). Causas de la pobreza de nuestro suelo. En Steven L. Driever y F. J. Ayala-Carcedo (Ed), La futura revolución española y otros escritos regeneracionistas (pp. 79-134). Madrid: Biblioteca Nueva.

Mapa del agua de la provincia de Alicante (2007). Alicante: Diputación de Alicante, Dpto. de Ciclo Hídrico.

Marco Molina, J. A., Matarredona Coll, E., Padilla A. (1998). Integración de los estudios del medio físico en la Ordenación del Territorio: valoración ecológico-paisajística del río Algar (Altea, Alicante). Investigaciones Geográficas, (20), pp.119-140.

Mateu Bellés, J. (1995). Planificación hidráulica de las Divisiones Hidrológicas (1865-1899). En A. Gil Olcina y A. Morales Gil (Eds), Planificación hidráulica en España (pp. 69-105). Alicante: Caja de Ahorros del Mediterráneo.

Morell y Gómez, F. (1866). Proyecto de Canal de riego para fertilizar terrenos de los términos de Callosa de Ensarriá, Altea, Polop, Nucía, Alfaz, Benidorm, Villajoyosa, Campello, San Juan, Muchamiel, Villafranqueza, Alicante y Elche. Imprenta de la viuda de D. Pedro Ibarra. Alicante.

Prado y Palacio, J. (1918). Estudio, aprobación y ejecución del plan de obras hidráulicas con aplicación al beneficio del agua para la Agricultura. Actas II CNR, Tomo I, (pp. 375-381). Sevilla.

Torregrosa Martí, Ma Teresa (2009). La gestión del agua en la Marina Baja (Alicante). Valencia: Temas de las Cortes Valencianas.

Vidal Olivares, J. (1986). Materiales para la historia económica de Alicante, Alicante (1850-1900). Alicante: Instituto Juan Gil-Albert, Diputación de Alicante.

Sesión inaugural del III Congreso Nacional de Riegos celebrado en Valencia en 1921. Discurso del Sr. Ministro D. Rafael Gasset. III CNR, Tomo I, pp. 62-77.

Sesión de apertura del V Congreso Nacional de Riegos celebrado en Valladolid en 1934. Discurso del Sr. Presidente de la República D. Niceto Alcalá Zamora. V CNR, Tomo I, pp. 43-52.

Sesión inaugural del IV Congreso Nacional de Riegos celebrado en Barcelona en 1927. Discurso del Barón de Esponellá. IV CNR, Tomo I, pp. 27-38.

Sesión inaugural del IV Congreso Nacional de Riegos celebrado en Barcelona en 1927. Discurso del Sr. Marqués Alonso Martínez. IV CNR, Tomo I, pp. 27-38. 